\title{
Mobile Learning Model for the Zimbabwe Higher Education Sector
}

\author{
LYDIA MAKETO \\ Curtin University, Perth, Australia
}

\begin{abstract}
With mobile technologies outpacing desktop computers this may be the ideal time for Zimbabwe universities to tap into m-learning. There is little research on m-learning implementation and adoption on a large scale in Zimbabwe universities. This study attempts to determine the feasibility of implementing m-learning in Zimbabwe by initially investigating students' readiness for m-learning. A qualitative approach was employed by conducting focus group discussions with 20 university students. The study shows that some students are ready for m-learning based on their exposure to m-learning and opportunities of increased engagement. To further confirm the findings of the focus group discussions a survey with a large cohort of students to establish students' readiness for m-learning in Zimbabwe universities should be conducted. With mobile technologies becoming more pervasive, this paper adds to the field of $\mathrm{HCI}$ as it discusses how students utilise mobile technologies to extend their learning. The paper is presented at MobileHCI 2020 Doctoral Consortium.
\end{abstract}

\section{CCS CONCEPTS}

- Human-centered computing; • Ubiquitous and mobile computing; • Empirical studies and mobile computing.;

\section{KEYWORDS}

M-learning, Mobile technologies, Universities, Developing countries

\section{ACM Reference Format:}

LYDIA MAKETO. 2020. Mobile Learning Model for the Zimbabwe Higher Education Sector. In 22nd International Conference on Human-Computer Interaction with Mobile Devices and Services (MobileHCI '20 Extended Abstracts), October 05-08, 2020, Oldenburg, Germany. ACM, New York, NY, USA, 3 pages. https://doi.org/10.1145/3406324.3409258

\section{INTRODUCTION}

The rapid increase globally in the use of connected mobile devices is redefining how teaching and learning occurs. Mobile technologies are a driving force behind education [3]. With mobile learning (mlearning) yet to be fully established in Zimbabwe universities, this paper investigates students' readiness for m-learning in Zimbabwe universities as part of a larger study that investigates factors that influence m-learning adoption in Zimbabwe universities. This paper addresses the following research question:

Permission to make digital or hard copies of part or all of this work for personal or classroom use is granted without fee provided that copies are not made or distributed for profit or commercial advantage and that copies bear this notice and the full citation on the first page. Copyrights for third-party components of this work must be honored For all other uses, contact the owner/author(s).

MobileHCI '20 Extended Abstracts, October 05-08, 2020, Oldenburg, Germany

(c) 2020 Copyright held by the owner/author(s).

ACM ISBN 978-1-4503-8052-2/20/10.

https://doi.org/10.1145/3406324.3409258
RQ: What are the students' readiness for mobile learning in Zimbabwe?

There is little research on m-learning implementation and adoption on a large scale in Zimbabwe universities. For Zimbabwe universities to implement m-learning on a wide scale it is important to understand if students are ready for this mode of learning.

\subsection{Background}

At the end of 2012, around 6.8 billion people had mobile phone subscriptions globally, representing growth in developing and developed regions [5.]. The cultural bias of mobile technologies, education systems and m-learning are predominantly of the Global North [11]. This can present challenges for developing countries that are pioneering $\mathrm{m}$-learning since such countries may have different education systems and have to deal with their own cultural biases.

\subsection{WHAT IS M-LEARNING?}

Initially, m-learning definitions were device-driven [4]. However, this has shifted to personal and social-driven definitions which take into consideration the technological affordances of the mobile technologies [1]. This paper considers the mobility of both the learners and the devices, and acknowledges that learning occurs across a broad spectrum.

\subsection{Why M-learning for Zimbabwe universities?}

Higher education institutions in Zimbabwe are currently in a series of crises due to a decline in economic growth resulting in underfunding coupled with high student enrolment [6]. This economic decline has greatly impacted the education system, and Zimbabwe's education system once rated the best in Africa, faces immense challenges [9]. In some developing countries like Zimbabwe, universities are the key to producing highly skilled manpower and are therefore central to the development of the country. There is a need to improve access to quality and cost-effective education in Zimbabwe. M-learning has the potential to remedy the poor education systems in developing countries.

\section{RESEARCH METHODS}

The study will take a mixed-methods approach. The study has started off with a qualitative approach, which will be followed with a quantitative approach. Focus groups were used to elicit learners' attitudes and experiences which cannot easily be obtained by other methods. Purposeful sampling was used to select focus group participants.

Analysis started during data collection, with notes being made from that stage. Thematic analysis was used to analyse the data, following the six-step process suggested by Braun and Clarke [2]. 


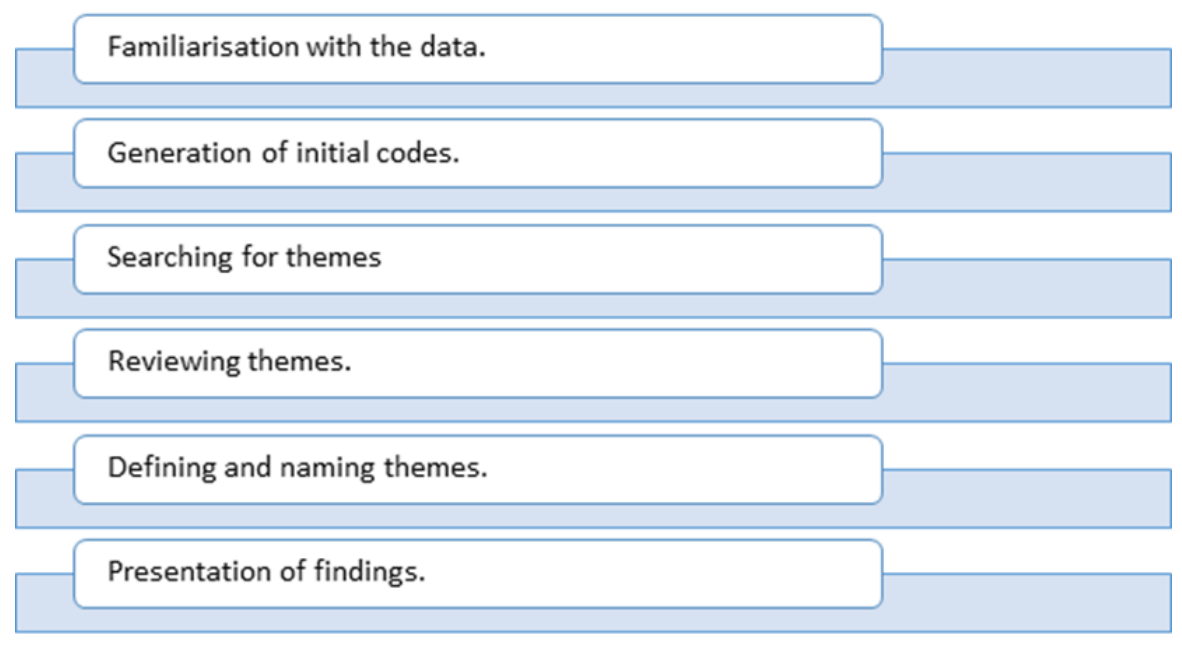

Figure 1: Thematic Analysis - (prepared by researcher)

While the steps are presented as a linear step-by-step procedure, the actual analysis is not linear but very iterative. The steps for the thematic analysis are shown in Figure 1. Three focus group discussions were conducted with a total of twenty students (11 Male, 9 Female). The discussions were recorded and then transcribed.

A hybrid approach was chosen for the thematic analysis. This incorporated the data-driven approach to the data collected, and the theory-driven approach. After the initial coding based on the research question and focus group discussion questions, coding was data-driven. The transcripts were read carefully to find useful text relevant to the research topic. The units of text addressing the same issue were grouped together under categories and sub-categories. NVivo 12 Pro software was used for coding.

\subsection{Research outcomes}

To address the RQ: What are the students' readiness for mobile learning in Zimbabwe? Two aspects of using mobile technologies in learning in the discussion guide were based on the following:

- Discuss learning activities you can perform using mobile devices

- What is your opinion about using mobile devices to extend learning activities?

\subsection{Learning activities using mobile devices}

According to students, learning activities available via mobile technologies were both active and passive learning activities. Active learning activities included researching for information, looking for video tutorials, answering questions in class using particular apps, developing web applications and use of apps for parts of the unit offered [8]. One student pointed out that m-learning could allow learners to acquire new skills and could be used by learners to develop professionally. Some comments on learning activities using m-learning by students are given below:
FG_Member8: "One lecturers, came with an app called Tolgate which can be used for attendance and it can also be used for answering questions during the lectures."

FG_Member9: "Our lecturer created a WhatsApp group and we use it to schedule dates for assessments and dates for submissions of chapters."

FG_Member17: “The University that I went to had a platform called Feeler a student portal. We didn't have to go for lectures. The lecturer would upload a video and you would do a quiz afterwards and you would submit it and gain feedback."

Although m-learning is yet to be implemented on a large scale in Zimbabwe universities, some students have had exposure to $\mathrm{m}$-learning. The exposure to different applications has either been brought to students by instructors or lecturers from outside the country or students who have been affiliated with institutions outside the country. Locally, some lecturers are taking the initiative to use mobile technologies for administrative roles such as scheduling dates for assessment submissions and giving learners access to course material.

\subsection{Using mobile devices to extend learning}

Students reported that use of mobile technologies in learning could extend learning through increased engagement. A number of students reported that m-learning was more engaging than the traditional method of learning that just had the instructor as the main source of knowledge [7]. One student highlighted that m-learning gave access to other sources of information, thereby reducing dependence on the teacher.

The findings on increased engagement because of m-learning suggest that with mobile technologies, the classroom will no longer be a prohibitive space for innovation and technology engagement and thus teaching and learning will be transformed from traditional approaches to unconventional methods of knowledge transfer [10]. It is not surprising that students find the m-learning mode of teaching/learning more engaging. Most of these students use mobile 
devices for social interaction already and these may be useful instruments for academic research. Some comments from students on increased engagement are given below:

FG_Member5: "It makes work easier in that if you have a problem you an easily contact someone for a solution."

FG_Member11: For example, we did design projects. So you could be facing a problem that someone already faced and solved. So I think you can easily solve that problem when you collaborate with others."

FG_Member12: "I think not only looking at the peers around you, I think on the Internet having forums would be helpful. You have large groups of people especially those in your field, so you ask a question to people and there is room for discussion."

\section{KEY RESULTS}

The study so far has shown that some university students are ready for m-learning based on their experiences with m-learning and the increased engagement offered by m-learning. Some students have had exposure to various applications either through their lecturers or affiliations to institutions beyond Zimbabwe borders. Some students have benefitted from the administrative role of $\mathrm{m}$ learning in which students are reminded of assessment submission schedules. However not all students have had experience with $\mathrm{m}-$ learning. It may be necessary to investigate students' knowledge on m-learning and whether they are willing to accept this mode of learning. There a variety of ways in which m-learning can be implemented on a large scale. In resource-constrained contexts this may start off with the administrative functions which can be further developed to extend learning outside the confines of physical buildings. Generalisation on students' readiness for $\mathrm{m}$ learning in Zimbabwe universities cannot be established based on the focus group discussions alone.

\section{REMAINING RESEARCH EFFORTS}

While the focus group discussions provided rich information a survey would enable researchers to gather data from a large cohort allowing for generalisations. The next phase for this study will be survey to establish students' readiness for m-learning.

\section{ISSUES TO DISCUSS IN THE CONSORTIUM}

In carrying out the survey would the study benefit more from participants who were part of the focus group discussions or not?

\section{REFERENCES}

[1] Baran. 2014. A Review of Research on Mobile Learning in Teacher Education. Journal of Educational Technology \& Society 17, 4, 17.

[2] Braun and Victoria Clarke. 2006. Using Thematic Analysis in Psychology. Qualitative research in psychology 3,2, 77-101.

[3] Crompton and Diane Burke. 2018. The Use of Mobile Learning in Higher Education: A Systematic Review. Computers \& Education 123, 53-64.

[4] Hwang and Chin-Chung Tsai. 2011. Research Trends in Mobile and Ubiquitous Learning: A Review of Publications in Selected Journals from 2001 to 2010. British Journal of Educational Technology 42, 4, E65-E70.

[5.] 2013. Ict Facts and Figures.

[6] Michael Kariwo. 2007. Widening Access in Higher Education in Zimbabwe. Higher Education Policy 20, 1, 45-59. http://dx.doi.org/10.1057/palgrave.hep. 8300142

[7] Lindsay. 2016. Transformation of Teacher Practice Using Mobile Technology with One-to-One Classes: M-Learning Pedagogical Approaches. British Journal of Educational Technology 47, 5, 883-892.

[8] Manuel, Aparicio-Martínez Pilar, Redel-Macías María Dolores, MP Dorado, Pinzi Sara and Martínez-Jiménez M Pilar. 2019. Characterization of Biodiesel Using Virtual Laboratories Integrating Social Networks and Web App Following a Ubiquitous-and Blended-Learning. Journal of cleaner production 215, 399-409.

[9] Wilbert Sadomba, Byron Chigwanda and Tarisai Manyati. 2015. Education in the Crucible of a Postcolonial Revolution: Community Reaction to the Challenges of Zimbabwe's Crisis. Social Dynamics 41, 2, 235-252.

[10] C Spangler, Anthony Rodi and Misty Kiernan. 2016. Case Study: Byod in the Higher Education Classroom: Distraction or Disruption? The Adoption of Spangler's 2016 Digital Human It Integration Charting System. Issues in Information Systems 17, 3.

[11] M Traxler. 2018. Learning with Mobiles in Developing Countries: Technology, Language, and Literacy. In Information and Technology Literacy: Concepts, Methodologies, Tools, and Applications, IGI Global, 774-790. 